\title{
The contribution to the modal analysis of the control system
}

\author{
Alžbeta Sapietová ${ }^{1 *}$, Filip Chovanculiak ${ }^{1}$, Vladimír Dekýšs ${ }^{1}$, Lukáš Gajdoš $^{2}$ \\ ${ }^{1}$ University of Žilina, Faculty of Mechanical Engineering, Univerzitná 1, 010 26, Žilina, Slovakia \\ ${ }^{2}$ Schaffler Slovakia, Dr G Schaefflera 1, Kysucké Nové Mesto, Slovak Republic
}

\begin{abstract}
This article deals with the analysis of the suitability of using selected solution methodologies while taking into account the different degrees of simplification used. Three ways of determining the first frequency of the mechanism were presented on the lever mechanism of the control circuit. The solution is carried out analytically, then via a calculation model in the program on the dynamics of systems elements MSC ADAMS, and lastly, an experimental measurement was carried out.
\end{abstract}

Keywords: Dynamics, Custom Frequency, Experiment, Analytical Computation, Match

\section{Introduction}

Understanding of the physical processes is essential to the proper proposal of the construction. It is therefore natural to come up with design besides relevant calculations or experiments. Those shall, based on knowledge of the designer, provide information on the anticipated features of the proposed object.

These calculations are carried out analytically or by using computational models in specialized computer programs [1]. In both of these approaches, there is some degree of simplification, for example, of the shape of the object, its material parameters, boundary or initial conditions [2]. When solving these analytically, these simplifications may be based on the requirement of the task being solvable. Computing programs, because they are complex, usually require the entry of a large number of input parameters, which are not always known. These parameters are often estimated or entered with their implicit values when one starts the computing task. It is therefore natural to assume that analytical and computer models can "live their own lives" and then provide corresponding matching or different results.

If a construction prototype is designed, it is possible to perform experimental measurements. The immediate results of the measurements and their processing shall take into account the specifics of experimental procedures. Then it can also be said that the experiment "lives its own life". In addition, the experiment may also bring about phenomena which the methodology for measuring does not take into account $[3,4,5]$.

If the results of the calculations and the experiment match, then we encounter this type of a claim: "The results of the calculations were confirmed by an experiment, or the results of

\footnotetext{
*Corresponding author: alzbeta.sapietova@fstroj.uniza.sk

Reviewers: Jozef Bocko, Josef Soukup
} 
the experiment were confirmed by calculation". However, various approaches in computational and experimental solutions can mean getting different results. It is preferable to talk about match or no match of results, and not about their confirmation. This issue is dealt with, for example, [6].

\section{Modal analysis}

Modal analysis is a tool that allows understanding the vibrations of structures, or parts of them. It uses the decomposition of the complex process of vibration into basic, so-called modal contributions. Each contribution is characterised by modal frequency, shape of the vibration [7,3], and damping. The knowledge of these data helps understand the transmission characteristics of the mechanical system as well, when we assess the responsiveness of the system to an alarm, for example, by analysing the selected element by vibrating it $[8,9]$. The response in this case may be unexpectedly high, which can happen, for example, in the creation of resonance in the system. It can be approximately zero in the analysed frequency, if the point of measuring the response is the nodal (zero) point of the dominant shape of the vibration for this natural frequency. In another case, evoking of an unwanted non-linear response may occur for instance.

Finding the presence of phenomena with large and often unacceptable amplitudes of vibration in the real system and looking for the cause of these phenomena is often the reason for doing such an analysis. Designated natural frequencies are then confronted with the results from practice by using computer modal analysis. This procedure can be considered the initial step for verifying the hypothesis about creating resonance in the system at its natural frequency [10].

In the article, a computation modal analysis in the selected mechanism will be carried out in the programme for dealing with the dynamics of object systems of the MSC. ADAMS. The results of this solution are then compared with the analytical method using Lagrange equations of the second type and the experiment. Finally, a comparison of the results obtained is made.

\section{Model of control system}

A 3D model of the analysed mechanism was imported from the NX CAD to the MSC. ADAMS in the parasolid format. The accuracy of the position of each of the members has been verified using the body markers [11].

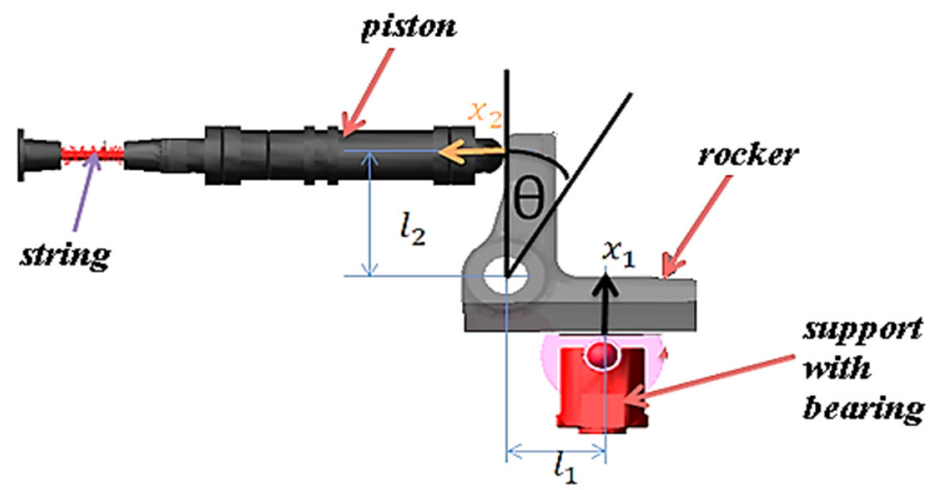

Fig. 1. The model of the analysed control system 
This mechanism scans the changes of position of the support by bearing, and through the lever, it transforms this position to the position of the piston. It is a system 1DOF in which the lever arm $\theta$ angle was chosen as an independent variable. The mechanism is composed of 12 members. For the sake of clarity, its representation was reduced (Fig. 1).

\subsection{Solution with MSC ADAMS}

A contact [12-14] was defined between the piston and the lever, and Coulomb's formulation was used for frictional force [15]. For springs used in the model, data on stiffness, damping and preload was entered [16].

Due to use of non-linearities, the linear model could not be used, or rather, it was not possible to use the Adams/Linear module. Therefore, the pulse stimulus was simulated by a very short force (pulse replacement) and the time dependence of the center of mass of piston was determined. It was a model with 1 DOF. Based on the stated dependency, the natural frequency of damped vibration was determined by the Fourier transformation of the generated signal. Fig. 2 shows the time course of response and its Fourier transformation. In this way, the frequency of $285 \mathrm{~Hz}$ was determined.
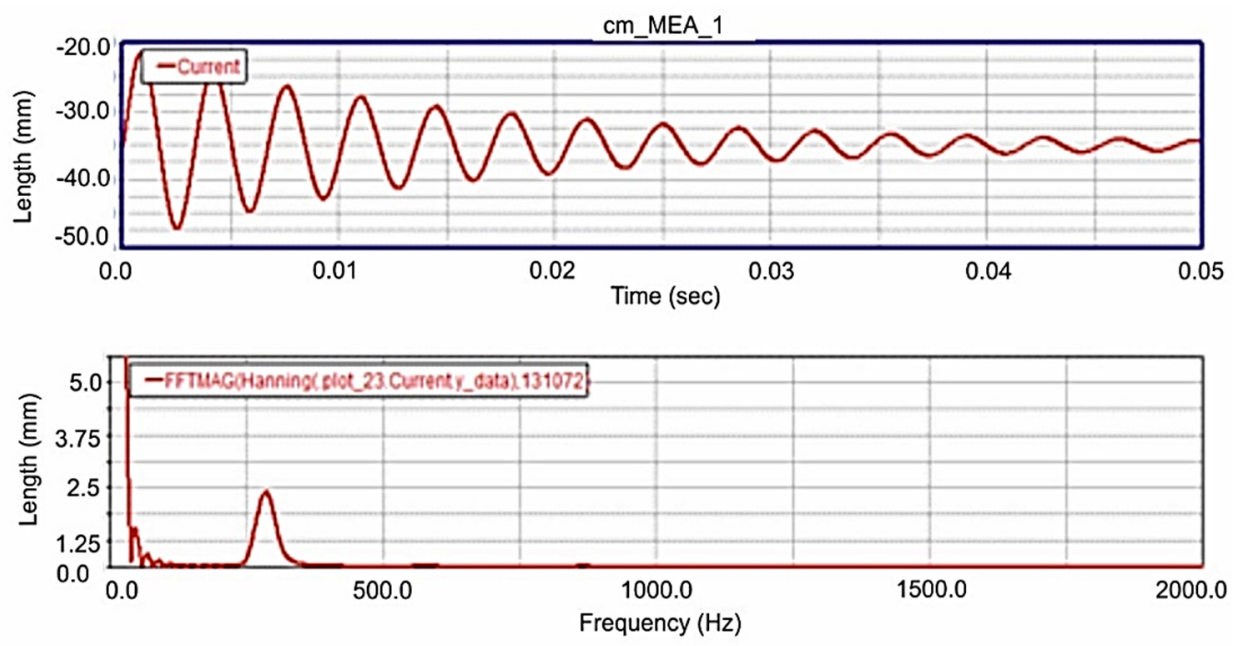

Fig. 2. Response of displacements of the piston on the impulse force, the time course and its FFT

\subsection{Solution with Lagrangian formulation}

The simplified estimation using Lagrange equations of the second kind was based on the following simplifications: it was a model with 1 DOF; no spring bias and damping was considered; there was no consideration of the contact between the piston and the lever or the presence of frictional force in this bond. The model with conservative forces was used using the following equation:

$$
\frac{d}{d t}\left(\frac{\partial E_{k}}{\partial \dot{\theta}}\right)-\frac{\partial E_{k}}{\partial \theta}+\frac{\partial E_{p}}{\partial \theta}=0
$$

where $E_{k}$ is the kinetic energy; $\mathrm{E}_{\mathrm{p}}$ is position energy; $\theta$ is the generalized coordinate (the angle of the rocker arm); generalized angular velocity and $t$ is time, [17-19].

In this way, the frequency of $284 \mathrm{~Hz}$ was determined. 


\subsection{Experimental solution}

The module of the control mechanism was mounted on the jig, and a miniature 3 axis accelerometer B\&K4520 was installed on the lever. The mechanism was stimulated by impulse hammer IH101-500 by striking the piston, and the impulse hammer and accelerometer were mounted on a four-channel USB module NI9234. Data was collected in NI SignalExpres and processed using the frequency response function (FRF). The output of the measurement is shown in Fig. 3, where a moderate peak around the desired frequency is marked.

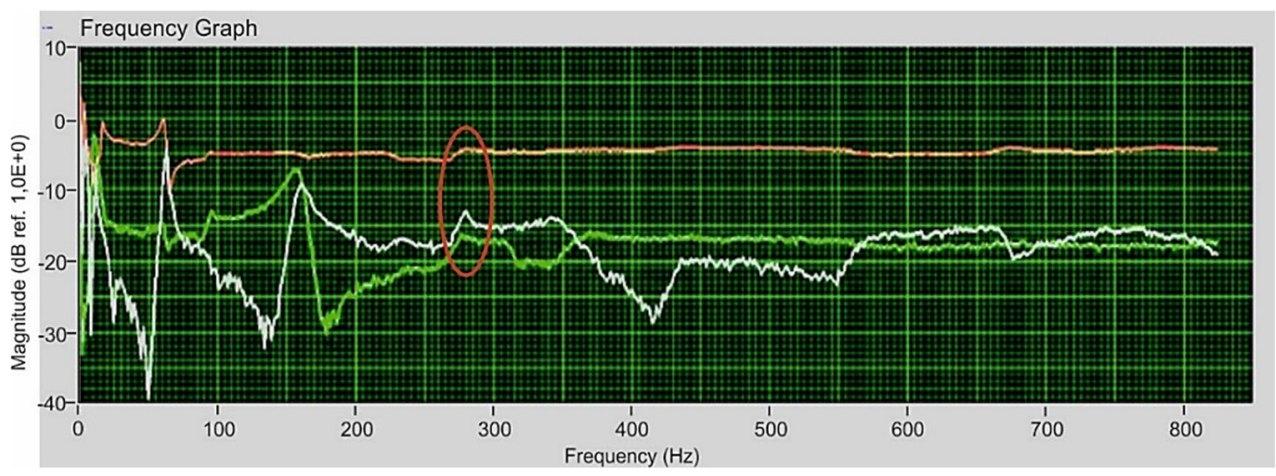

Fig. 3. FRF function for all three measuring channels on a lever. A moderate peak is marked on the expected resonant frequency, more precisely on $275 \mathrm{~Hz}$.

Although there is a readable peak around $275 \mathrm{~Hz}$ in the amplitude spectrum on Fig.3, but phase characteristics did not show sufficient change around this frequency which would generally result from a change of approximately $3.14 \mathrm{rad}$ before and after the resonance peak.

At first glance, everything is fine. However, the results of the experiment point to the fact that the above peak is less pronounced, demonstrable only intuitively. This can be caused by making a measurement on a real-life control system module that "lives its own life" independent of our simplifications used in the previous computational models.

\section{Conclusion}

Three ways of determining the first custom frequency of the mechanism were presented on the lever mechanism of the control circuit. The individual ways used a different degree of simplification.

In the Lagrangian formulation for the analytical solution absorption was neglected, and contact and presence of non-conservative forces was not taken into account.

In a computer model in MSC ADAMS a more comprehensive approach was used, when also damping and spring preload data was entered; the contact between the lever and the piston and Coulomb friction model were taken into account at the point of contact. The results for the first natural frequency were, despite the simplifications, identical.

The result of the experimental measurement provided a result with an estimated insignificant resonance frequency deviating by about $5 \%$ from the values obtained by the calculation.

This article aimed at presenting an approach to solving the estimation of natural frequency of a non-linear system in MSC ADAMS. In our opinion, on the basis of the simplifications used, we would like to once again reiterate disagreement with the claims such as: the 
calculation was confirmed by the experiment or the experiment was validated by the calculation.

This paper was supported by VEGA 1/0795/16 and KEGA 017ŽU-4/2017.

\section{References}

1. P. Orsansky, B. Ftorek, P. Durcansky, Mathematical Model of a Closed Hot Air Engine Cycle Using MATLAB (R)/Simulink (R), AIP Conference Proceedings, 1608, 173176 (2014)

2. Z. Poruba, J. Szweda, J. Podešva, Boundary Conditions and Constraint Equations for Simulation of Energy Exchange. Applied Mechanics and Materials, 315, 929-935 (2013)

3. J. Vavro, J. Vavro, Jr., P. Kovacikova, R. Bezdedova, The optimisation of the materials properties for the passenger cars in dependence on defect distribution at the dynamic loading, Procedia Engineering, 136, 114-119, (2016)

4. D. Stancekova, M. Sajgalik, J. Petru, N. Naprstkova, P. Balaz, Implementation of coating for failure elimination of dial gauges. METAL 2015 Conference Procedings of the 24th International Conference on Metallurgy and Materials, 1162-1169, (2015)

5. D. Barta, M. Mruzek, Importance of real operating parameters for design of public transport vehicles drive. Scientific journals of the maritime university of Szczecinzeszyty naukowe akademii morsikiej w Szczecinie, 39(111), 5-10, (2014)

6. M. Richardson, Modal analysis versus finite-element analysis. Sound \& vibration, 39(9), 5-9, (2005)

7. S. Miláček, Modální analýza mechanických kmitů. 2.vyd., Vydavatelství ČVUT, 154 s. (1991)

8. M. Sága, L. Jakubovičová, Simulation of vertical vehicle non-stationary random vibrations considering various speeds. Scientific Journal of Silesian University of Technology - Series Transport, 84, 113-118 (2014)

9. T. Harcarik, J. Bocko, K. Maslakova, Frequency analysis of acoustic signal using the Fast Fourier Transformation in MATLAB, Procedia Engineering, 48, 199-204, (2012)

10. M. Nad, L. Cicmancova, Effect of Shape Parameters on the Modal Properties of Stepped Ultrasonic Concentrator. Applied Mechanics and Materials, 309, 43-49, (2013)

11. M. Macko, K. Tyszczuk, G. Śmigielski, J. Flizikowski, A. Mroziński, The use of CAD applications in the design of shredders for polymers. MATEC, 157, 02027, (2018)

12. M. Dudziak, G. Domek, A. Kołodziej, K. Talaśka, Contact Problems Between the Hub and the Shaft with a Three-angular Shape of Cross-section for Different Angular Positions. Procedia Engineering, 96, 50-58, (2014)

13. J. Podešva, J. Szweda, Z. Poruba, The Substructures Technique Including Contact Problem. Applied Mechanics and Materials, 315, 884-888, (2013)

14. M. Zmindak, P. Pastorek, P. Falat, M. Sapieta, Hardening monitoring and contact stress analysis of test samples, Proceedings of the institution of mechanical engineers part $\mathrm{f}$ journal of rail and rapid transit, 230(1), 253-257, (2016)

15. L. Jakubovičová, M. Sága, M. Vaško, Numerical study of influence of mutual slewig of roller bearing rings on the principal stresses at contact area. Scientific journal of Silesian University of Technology - Series Transport, 84, 83-91 (2014)

16. P. Kassay, J. Homisin, P. Copan, M. Urbansky, Verification of torsional oscillating mechanical system dynamic calculation results. Scientific journal of silesian university of technology-series transport, 84, 29-34, (2014) 
17. J. Vavro, Jr., J. Vavro, P. Kovacikova, R. Bezdedova, Kinematic and dynamic analysis of the manipulator for removal of rough tyres, Procedia Engineering, 136, 120-124, (2016)

18. J. Famfulik, J. Mikova, M. Richtar, R. Halama, Random vector approach to the calculation of the number of railway vehicles to hold in reserve, Tehnicki vjesniktechnical gazette, 24(1), 7-14, (2017)

19. P. Kopas, M. Blatnický, M. Sága, M. Vaško, Identification of mechanical properties of weld joints of AlMgSi07.F25 aluminium alloy. Metalurgija 56 (1-2), 99-102 (2017) 